\title{
ECTD Submission Type Terminology
}

National Cancer Institute

\section{Source}

National Cancer Institute. eCTD Submission Type Terminology. NCI Thesaurus. Code C97190.

Terminology developed to support eCT D Submission Types. 